\title{
Cerebral metabolic rate for glucose during the first six months of life: an FDG positron emission tomography study
}

Anne Kinnala, Hanna Suhonen-Polvi, Tuula Äärimaa, Pentti Kero, Heikki Korvenranta, Ulla Ruotsalainen, Jörgen Bergman, Merja Haaparanta, Olof Solin, Pirjo Nuutila, Uno Wegelius

\begin{abstract}
Aim-To measure the local cerebral metabolic rate for glucose (LCMRGlc) in neonatal brains during maturation using positron emission tomography (PET) and 2-[18F]fluoro-2-deoxy-D-glucose (FDG). Methods-Twenty infants were studied using PET during the neonatal period. The postconceptional age ranged from 32.7 to 60.3 weeks. All infants had normal neurodevelopment and were normoglycaemic. The development of the infants was carefully evaluated (follow up 12-36 months) clinically, and by using a method based on Gesell Amatruda's developmental diagnosis. LCMRGlc was quantitated using PET derived from FDG kinetics and calculated in the whole brain and for regional brain structures.
\end{abstract}

Results-LCMRGlc for various cortical brain regions and the basal ganglia was low at birth (from 4 to $16 \mu \mathrm{mol} / 100 \mathrm{~g} /$ minute). In infants 2 months of age and younger LCMRGlc was highest in the sensorimotor cortex, thalamus, and brain stem. By 5 months, LCMRGlc had increased in the frontal, parietal, temporal, occipital and cerebellar cortical regions. In general, the whole brain LCMRGlc correlated with postconceptional age $(r=0.90 ; P<0.001)$. The change in the glucose metabolic pattern observed in the neonatal brain reflects the functional maturation of these brain regions.

Conclusion-These findings show that LCMRGlc in infants increases with maturation. Accordingly, when LCMRGlc is measured during infancy, the postconceptional age has to be taken into account when interpretating the results.

(Arch Dis Child 1996; 74: F153-F157)

Keywords: cerebral metabolic rate of glucose, positron emission tomography.

There have only been a few positron emission tomography (PET) studies of $2-\left[{ }^{18} \mathrm{~F}\right]$ fluoro-2deoxy-D-glucose (FDG) during the first months of life in the human infant. ${ }^{12}$ All reference values for the normal local cerebral meta- bolic rate for glucose (LCMRGlc) by various PET centres have been measured in healthy adults. ${ }^{3}$ However, to describe the normal pattern of LCMRGlc during infancy in infants with neurological disorders LCMRGlc needs to be ascertained. Human brain maturation is incomplete at birth and during development the brain undergoes anatomical and functional changes. Brain development includes proliferation of the neurones, their migration to specific sites, a series of organisational events, and myelin formation. ${ }^{4}$ The timing of these events occurs from the second month of gestation to adult life. During the first three months of life infant development is fastest in behavioural, neurophysiological, and anatomical function. ${ }^{4}$

Previous studies on developing brain have demonstrated a series of changes which affect cerebral glucose utilisation. These changes include increases in the concentrations of the glucose transporter proteins in the blood-brain barrier and in the neurones and glia. ${ }^{5}$ The noninvasive measurement of LCMRGlc with PET, ${ }^{6}$ using FDG as a tracer, is a widely used technique to study LCMRGlc in vivo in the human brain. ${ }^{7}$ LCMRGlc undergoes dynamic maturational changes during development from birth to adulthood: this has been demonstrated in the cat, ${ }^{8}$ and in the human infant. ${ }^{1}$ These changes are related to neurobehavioural developmental milestones.

We measured LCMRGlc using PET in newborn infants with suspected hypoxic-ischaemic brain injury ${ }^{9}$ or hypoglycaemia. Preliminary results have been presented in an earlier study. ${ }^{10}$ From these studies we have now selected 20 infants who developed normally during follow up. We aimed to determine normal values for LCMRGlc during the first months of life.

\section{Methods}

From over 150 infants and children measured for LCMRGlc between 0 and 18 years, we selected retrospectively 20 babies. Of these, 12 were selected from our research protocol designed to evaluate suspected hypoxicischaemic brain injury. ${ }^{9}$ The other eight infants were evaluated with FDG-PET after neonatal 
symptomatic hypoglycaemia. ${ }^{11}$ The outcome of the 20 neonates seemed to be normal during follow up and they remained neurodevelopmentally normal (follow up 12 to 36 months). The developmental assessment included a careful neurological examination by a neuropaediatrician, or a paediatrician and a physiotherapist. The oldest 12 children were studied according to the Manual of Developmental Diagnosis. ${ }^{12}$ There were eight girls and 12 boys, and two babies were studied twice; thus altogether, 22 PET studies were included into the study. These infants were born at 25-41 gestational weeks ( 14 were preterm), and at the time of PET investigation, were aged $32 \cdot 7-60 \cdot 3$ postconceptional weeks and 1-148 postnatal days (nine preterm babies aged 32-37 postconceptional weeks). Birthweight ranged from $720-4970 \mathrm{~g}$, and the mean weight of infants at the time of PET study was $4128 \mathrm{~g}$ (range $1945-7590 \mathrm{~g}$ ). Three infants were large for gestational age babies and one infant was small for gestational age. Infants were treated at the neonatal ward of Turku University Hospital. The study protocol was approved by the Ethics Committee of Turku University Hospital. Written parental consent was obtained.

PET studies were carried out during postprandial sleep one hour after feeding, without sedation, as we have described before. ${ }^{9}{ }^{13}$ Two venous catheters were inserted, one in a peripheral vein for the injection of FDG and another for blood sampling. For the measurement of brain, 3.7 (SD) $0.5 \mathrm{MBq} / \mathrm{kg}$ of FDG was injected intravenously and dynamic scanning was started. Dynamic scanning of the thoracic region was started simultaneously and continued for 7 minutes $(12 \times 10$ seconds, $10 \times 30$ seconds). Thereafter, dynamic scans were taken from the brain ( $10 \times 120$ seconds). The brain study was started about 45 minutes after the tracer injection. Blood samples were obtained five to 10 times during the PET study for the input function, as described before. ${ }^{13}$ Plasma glucose concentrations were measured three times during the study period; these were constant and all patients were normoglycaemic over the period investigated (plasma glucose $5.5(1.4) \mathrm{mmol} / \mathrm{l})$. Total volume of blood collected did not exceed $5 \mathrm{ml}$.

FDG was synthesised, as described by Hamacher et al. ${ }^{14}$ The specific activity at the end of the synthesis was about $2 \mathrm{Ci} / \mu \mathrm{mol}$ and the radiochemical purity exceeded $98 \% .^{15}$

PET studies were performed, as described before. ${ }^{13}$ The infant was lying supine in an

Local cerebral metabolic rates for glucose ( $\mu \mathrm{mo \nu} 100 \mathrm{~g} /$ minute) for selected brain regions during development seen with PET

\begin{tabular}{|c|c|c|c|c|c|}
\hline \multirow[b]{2}{*}{ Structure } & \multicolumn{5}{|c|}{ Postconceptional age (weeks) } \\
\hline & $32-37(n=8)$ & $38-42(n=6)$ & $43-48(n=2)$ & $49-56(n=2)$ & Over $56(n=4)$ \\
\hline \multicolumn{6}{|l|}{ Cerebral cortex: } \\
\hline Frontal & $6.5(1.9)$ & $7 \cdot 6(3.4)$ & $8.0(2.0)$ & $15 \cdot 1(0 \cdot 7)$ & $24 \cdot 2(4 \cdot 6)$ \\
\hline Temporal & $6.2(1.9)$ & $8.5(3.3)$ & $7 \cdot 2(0.0)$ & $16 \cdot 4(1 \cdot 7)$ & $20.5(2.0)$ \\
\hline Occipital & $5 \cdot 8(1 \cdot 3)$ & $8.7(3.0)$ & $8.0(1.5)$ & $15.8(0.5)$ & $25 \cdot 0(3 \cdot 1)$ \\
\hline Sensorimotor & $7 \cdot 4(3 \cdot 6)$ & $9.0(4.4)$ & $12 \cdot 2(2 \cdot 5)$ & $22 \cdot 0(5 \cdot 7)$ & $33 \cdot 0(1 \cdot 7)$ \\
\hline Thalamus & $9 \cdot 3(4 \cdot 3)$ & $12 \cdot 1(4 \cdot 9)$ & $16 \cdot 7(6 \cdot 1)$ & $20.0(0.3)$ & $34 \cdot 4(3 \cdot 2)$ \\
\hline Brain stem & $10.4(3.5)$ & $13 \cdot 3(5 \cdot 6)$ & $20 \cdot 1(0 \cdot 0)$ & $15.8(0.4)$ & $23.4(1.9)$ \\
\hline Cerebellum & $9 \cdot 4(3.5)$ & $11.9(4 \cdot 3)$ & $11 \cdot 1(4 \cdot 2)$ & $15 \cdot 3(2.9)$ & $14 \cdot 4(8 \cdot 6)$ \\
\hline Whole brain & $5 \cdot 5(1 \cdot 4)$ & $7 \cdot 2(2 \cdot 6)$ & $7.4(0.6)$ & $12 \cdot 2(0 \cdot 2)$ & $18 \cdot 7(1 \cdot 6)$ \\
\hline
\end{tabular}

*Values represent means (SD). All brain regions were not available in every subject. eight-ring ECAT 931/08-12 tomograph (Siemens/CTI Corp, Knoxville, TN, USA) with the imaging planes oriented parallel to the canthomeatal line. The axial resolution was $6 \cdot 7$ $\mathrm{mm}$ and $6.5 \mathrm{~mm}$ in the spatial plane (full width of half the maximum), measured according to the method of Spinks et al 1988. ${ }^{16}$

Regions of interest were drawn on Hanning filtered $256 \times 256$ PET reconstructions (cutoff frequency 0.5 ) which were corrected for deadtime and decay. The attenuation was corrected with the calculated method to avoid extra radiation and to save time. The blood time-activity curve was derived from a region of interest drawn over dynamic PET images of the left heart cavity (0-7 minutes from injection) and venous plasma samples (7-50 minutes from injection). ${ }^{13}$ The whole brain regions of interest were placed on four representative slices around the thalamus. Elliptical regions of interest were drawn on each transaxial slice visualising different brain structures using anatomical atlases as reference. ${ }^{17}$ The mean activity concentrations of these individual regions were calculated. The three compartment model of FDG was used, as described before. ${ }^{6}$ Plasma and tissue timeactivity curves were treated with graphic analysis to quantitate the fractional rate of tracer phosphorylation, $\mathrm{K}_{\mathrm{i}}{ }^{18}$ The rate of glucose utilisation was calculated by multiplying $K_{i}$ by the plasma glucose concentration, $[\mathrm{Glc}]_{\mathrm{p}}$, and dividing by a lumped constant (LC) ${ }^{19}$ :

$$
\mathrm{rGU}=\left(\mathrm{K}_{\mathrm{i}} \times[\mathrm{Glc}]_{\mathrm{p}}\right) / \mathrm{LC} \text {. }
$$

The lumped constant is used to correct for differences in the transport and metabolism of FDG and glucose. ${ }^{7}$ In this study we used an LC of 0.52 , the measured value from human studies. ${ }^{20}$

\section{ANALYTICAL AND STATISTICAL PROCEDURES} Plasma glucose concentrations were measured using the glucose oxidase method with a glucose analyser (GWB micro-stat GM7, Analox Instruments, London, England). Statistical analyses were performed using the BMDP program, ${ }^{21}$ correlations were performed by bivariate plots. A probability level of 0.05 was considered significant. Results are given as mean and standard deviation (SD).

\section{Results}

WHOLE BRAIN

LCMRGlc was strongly associated with postconceptional age. In preterm infants (postconceptional age ranged from 32-37 weeks), the whole brain LCMRGlc was $5.5(1.4) \mu \mathrm{mol} /$ $100 \mathrm{~g} /$ minute (table 1 ). In term infants (aged 38-42 postconceptional weeks) the whole brain LCMRGIc was $7 \cdot 2(2 \cdot 6) \mu \mathrm{mol} / 100 \mathrm{~g} /$ minute (table 1). The whole brain LCMRGlc reached the value of $18.7(1.6) \mu \mathrm{mol} / 100 \mathrm{~g} /$ minute in infants aged 56-60 postconceptional weeks. In general, the whole brain LCMRGlc correlated with postconceptional age $(r=0.90)$ (fig $2 \mathrm{C}$ ) and with postnatal age $(r=0.84 ; P<0.001)$. 


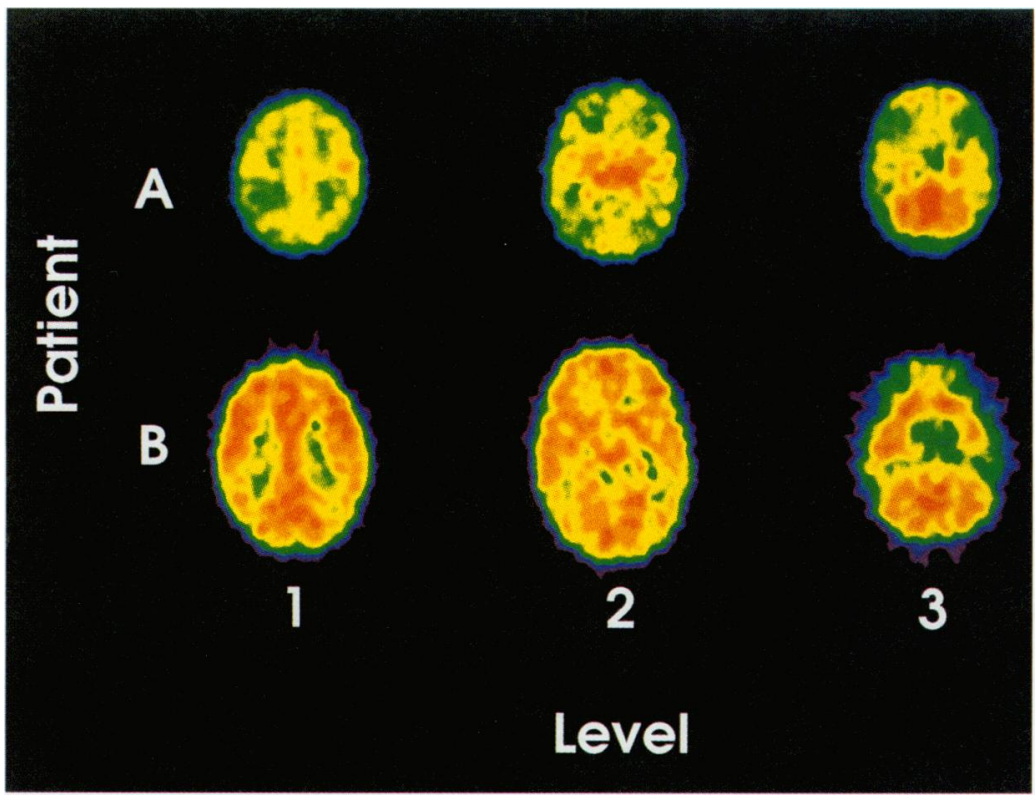

Figure 1 Distribution of FDG and change in LCMRGlc pattern with increasing postconceptional age. For both patients ( $A$ is 37 weeks and $B$ is 60 weeks postconceptional age), three tomographic levels of scan were obtained. Level 1 is taken through the cingulate cortex, level 2 through the mid portion of the thalamus, and level 3 through the cerebellum.

Qualitative inspection of the image sets (fig 1) revealed maturational changes in LCMRGlc in infants with increasing age.

Two babies were studied twice, and these two examinations were treated as independent scans in all analyses. To avoid the complications of repeated measures, the correlations were performed without the second scans from these two babies. The correlations do not differ from these results.

THALAMUS, CEREBELLUM, AND BRAIN STEM In infants aged 2 months and younger, LCMRGlc was active in subcortical areas (thalami, brain stem) and the sensorimotor cortex (fig 1). The regional thalamic LCMRGlc values ranged from 5 to $20 \mu \mathrm{mol} / 100 \mathrm{~g} /$ minute before the postconceptional age of 42 weeks, and these values reached $35 \mu \mathrm{mol} / 100$ $\mathrm{g} /$ minute at the age of $56-60$ postconceptional weeks. During the first months of life the LCMRGlc for the cerebellum ranged from 5-16 $\mu \mathrm{mol} / 100 \mathrm{~g} / \mathrm{minute}$, and a maturational rise in LCMRGlc was found. The brain stem was relatively advanced already at birth, the LCMRGlc values ranged 4-20 $\mu \mathrm{mol} / 100$ $\mathrm{g} /$ minute, and reached the value of 23 $\mu \mathrm{mol} / 100 \mathrm{~g} / \mathrm{minute}$ at the age of $56-60$ postconceptional weeks (table 1). The LCMRGlc increased with postconceptional age in the thalamic region $(r=0.86 ; P<0.001)$, in the cerebellum $(r=0.62 ; P<0.005)$, and in the brain stem $(r=0.72 ; \mathrm{P}<0.001)$ (fig $2 \mathrm{~B})$.

\section{CORTICAL REGIONS}

LCMRGlc for all cortical brain regions was low (from 4 to $12 \mu \mathrm{mol} / 100 \mathrm{~g} / \mathrm{minute}$ ) in the preterm infants (fig 1, table 1). In the preterm and term infants LCMRGlc was the most active in the sensorimotor cortex (fig 1) and it ranged from 4 to $16 \mu \mathrm{mol} / 100 \mathrm{~g} / \mathrm{minute}$. In the frontal cortex LCMRGlc was low in preterm and also at term infants (from 3.5 to 15 $\mu \mathrm{mol} / 100 \mathrm{~g} /$ minute) and it increased with advancing postconceptional age (fig $2 \mathrm{~A}$ ). The temporal and the occipital cortical LCMRGlc values were low at birth (4-10 $\mu \mathrm{mol} / 100$ $\mathrm{g}$ /minute). LCMRGlc correlated positively with advancing postconceptional age in the sensorimotor cortex $(\mathrm{r}=0.89 ; \quad \mathrm{P}<0.001)$, frontal cortex $(\mathrm{r}=0.88 ; \mathrm{P}<0.001)$, temporal cortex $(r=0.90 ; \quad P<0.001)$, and occipital cortex $(r=0.79 ; P<0.001)$.

\section{Discussion}

Our results show that whole brain and regional LCMRGlc were strongly associated with postconceptional age. We believe that our data are
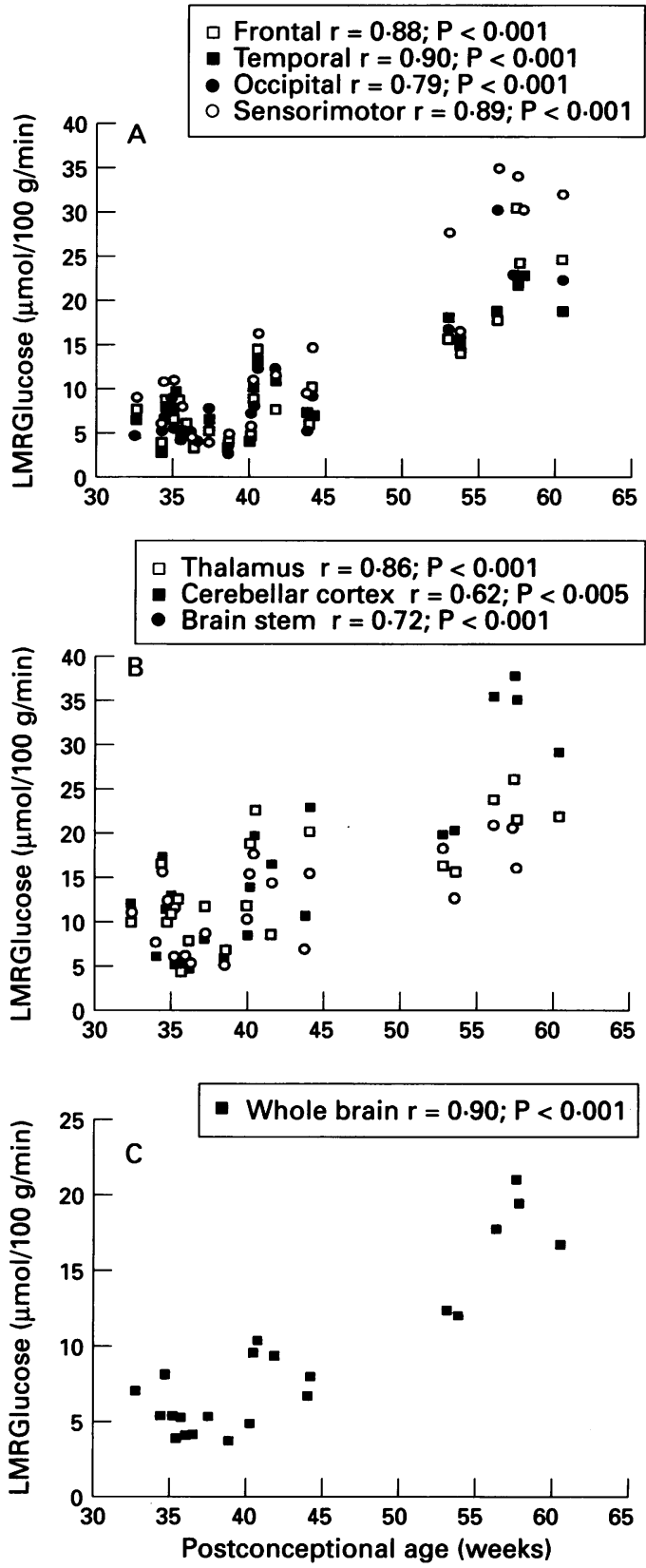

Figure 2 Values of LCMRGlc for selected brain regions plotted as a function of postconceptional age (weeks) for all infants. Points represent individual values of LCMRGlc. (A) Selected regions of cerebral cortex: frontal, temporal, occipital and sensorimotor; (B) thalamus, brain stem, and cerebellum; (C) whole brain. 
representative of the normative state, because all infants were normoglycaemic, received no drugs during the time of the PET study, and developed normally during the follow up. For ethical reasons, entirely asymptomatic normal children cannot be studied with PET. The age related changes in cortical glucose metabolism have been studied in humans ${ }^{3}$ and also in animals. ${ }^{22}$ Our data on the pattern of the neonatal frontal cortical LCMRGlc show a temporal maturational rise in other cortical regions. In the neonatal period (the first four weeks of life), the frontal cortex developed slower in a previous study of five infants under 5 months old. The maturational increase in LCMRGlc was seen in the anterior parietal, temporal, and calcarine cortical regions by about 3 months. ${ }^{1}$ In that study three infants were taking anticonvulsive phenobarbital daily. In animal studies early neonatal phenobarbital exposure decreased LCMRGlc by 12 to $43 \%$. Phenobarbital also changed the maturation pattern seen in local cerebral glucose utilisation compared with controls. ${ }^{23}$ The effect of phenobarbital on cerebral glucose metabolism has also been studied in adult patients using PET with FDG, and it reduced LCMRGlc by $37 \% .{ }^{24}$ For these reasons it was important to select patients without any medication for this study.

The effects of maturation on brain glucose metabolism in children have been studied using PET and FDG. These studies have documented the age related changes in children aged 5 days to 15 years. Unfortunately these studies have consisted of only a few newborn infants. ${ }^{12}$ The correlation with postconceptional age and regional LCMRGlc was also shown in the present study, reflecting the cerebral maturation already seen in preterm infants. Our data were based on postconceptional age and our studies show that conceptional age is a major determinant of glucose utilisation. LCMRGlc values are very low in the youngest babies, especially in preterm infants. Our results complete the previous findings and illustrate the changes of LCMRGIc, especially in the youngest infants.

Quantification of the cerebral glucose metabolism by PET is technically very demanding in children. Ethically it is not possible to use invasive arterial catheters or to sample large blood volumes in small infants for PET alone. To minimise the need for blood samples we used the combined curve where left ventricular activity concentration during the first 5 minutes of the study was combined with two to 10 venous whole blood samples during the rest of the study. ${ }^{13}$

LC is a mathematical factor that accounts for differences in the transport and phosphorylation of FDG and glucose. In newborn infants LC may differ greatly from normal adult values. Furthermore, the value of LC may vary considerably in ischaemic and infarcted tissue, and during hypoglycaemia and hyperglycaemia. Errors in calculated glucose metabolism can occur unless individual constants are measured. The measurement of LC values in children is difficult to perform and requires substantial blood volumes. We used measured LC for young adult brain. ${ }^{20}$ Our patients were normoglycaemic over the period investigated; LC is relatively stable under normoglycaemic physiological conditions. ${ }^{19}$ Although we studied infants who were not completely normal, we believe that the data are reasonably representative of the normal state, because all these infants had episodic neurological events but remained neurodevelopmentally normal.

Our study contributes to the data of maturational changes in cerebral glucose metabolism in infants under 7 months old. These results also provide insight into the LCMRGIc values in preterm infants and also show a new finding of the developmental change of LCMRGIc in the frontal cortical region. The postconceptional age rather than postnatal age is the major determinant of glucose utilisation rate. The change of glucose utilisation is uniform and correlates with normal functional maturation.

This study was financially supported by the Arvo and Lea YIppö Foundation. The Turku Medical Cyclotron Laboratory provided the FDG. We thank the staff at the departments of paediatrics and nuclear medicine. We also thank Mrs Kirsi
Kainonen and Tina Lemetyinen, physiotherapists, for their assistance in the neurological follow up of the patients, and Mrs Satu Ekblad, RN, for practical help.

1 Chugani HT, Phelps ME, Mazziotta JC. Positron emission tomography study of human brain functional development. Ann Neurol 1987; 22: 487-97.

2 Chugani HT, Phelps ME. Maturational changes in cerebral function in infants determined by $18 F D G$ positron emisfunction in infants determined by 18FDG

3 wang Gene-J, Volkow ND, Wolf AP, Brodie JD, Hitzemann RJ. Intersubject variability of brain glucose metabolic measurements in young normal males. $\mathcal{F} \mathrm{Nucl}$ metabolic measurements

4 Volpe J. Neurology of the newborn. Philadelphia: W B Saunders Company, 1987

5 Vannucci SJ, Seaman LB, Brucklacher RM, Vannucci RC. Glucose transport in developing rat brain: Glucose transporter proteins, rate constants and cerebral glucose utilization. Mol Cell Biochem 1994; 140: 177-84.

6 Huang SC, Phelps ME, Hoffman EJ, Sideris K, Selin CJ, Kuhl DE. Noninvasive determination of local cerebral metabolic rate of glucose in man. Am f Physiol 1980; 238 E69-82.

7 Phelps ME, Huang SC, Hoffman EJ, Selin C, Sokoloff L Kuhl DE. Tomographic measurement of local cerebral glucose metabolic rate in humans with (F-18)2-fluoro-2glucose metabolic rate in humans with (F-18)2-fluoro-26: $371-88$.

8 Chugani HT, Hovda DA, Villablanca JR, Phelps ME, Xu W. Metabolic maturation of the brain: a study of local cerebral glucose utilization in the developing cat. $f$ Cereb Blood Flow Metabol 1991; 11: 35-47.

9 Suhonen-Polvi H, Kero P, Korvenranta H, Ruotsalainen U, Haaparanta M, Bergman J, et al. Repeated fluorodeoxyglucose positron emission tomography of the brain in infants with suspected hypoxic-ischaemic brain injury. Eur $\mathcal{F ~ N u c l ~ M e d ~ 1 9 9 3 ; ~ 2 0 : ~ 7 5 9 - 6 5 . ~}$

10 Suhonen-Polvi $H$, Ruotsalainen U, Kero P, Korvenranta $H$, Bergman J, Haaparanta $M$, et al. Functional development of the brain during the first months of life: A (18-F) FDG positron emission tomography study. Fetal Diagn Ther 1992; 7: 37-8.

11 Kinnala A, Nuutila P, Ruotsalainen U, Teräs M, Bergman $J$, Haaparanta $M$, et al. Neonatal hypoglycaemia effects on cerebral glucose utilization in newborn infants: a (18F)FDG positron emission tomography (PET) study. In: Medical application of cyclotrons VI. Turku: University In: Medical application of cyclotrons

12 Knobloch H, Stevens F, Malone AF. The administration and interpretation of the revised Gesell and Amatruda developmental and neurologic examination. In: Manual of developmental diagnosis. Houston: Developmental Evaluation Materials Inc, 1987

13 Suhonen-Polvi H, Ruotsalainen U, Kinnala A, Bergman J, Haaparanta $M$, Teräs $M$, et al. FDG-PET in early nfancy: simplified quantification methods to measure cerebral glucose utilization. $₹ \mathrm{Nucl}$ Med 1995; 36: 1249-54.

14 Hamacher K, Coenen HH, Stöcklin G. Efficient stereospecific synthesis of no-carrier-added $2-[18 \mathrm{~F}]$-fluoro2-deoxy-D-glucose using aminopolyether supported nucleophilic substitution. $f$ Nucl Med 1986; 27: 235-8. 
15 Bergman J, Haaparanta M, Solin O. Computer controlled synthesis of 2-F-Fluoro-2-Deoxy-D-Glucose (FDG). In The Abo Akademi Accelerator Triennial Report 1990-92. Turku: University of Turku, 1992: 76-9.

16 Spinks TJ, Jones T, Gilardi MC, Heather JD. Physical performance of the latest generation of commercial positron scanner. IEEE Trans Nucl Sci 1988; 35: 721-5.

17 Aquilonius S-M, Eckernäs S- $\AA$. A colour atlas of the human brain. Stockholm: Esselte Studium, 1980.

18 Patlak CS, Blasberg RG. Graphical evaluation of blood-tobrain transfer constants from multiple-time uptake data. Grain transfer constants from multiple-time uptake data. 584-90.

19 Sokoloff L, Reivich M, Kennedy C, Des Rosiers MH, Patlak $\mathrm{CS}$, Pettigrew KD, et al. The [14C]deoxyglucose method for the measurement of local cerebral glucose utilization theory, procedure, and normal values in the conscious and anesthetized albino rat. $\mathcal{F}$ Neurochem 1977; 28: 897-916.
20 Reivich $M$. Cerebral glucose consumption: methodology and validation. In: Reivich $M$, Alavi A, eds. Positron emission tomography. New York: Alan R Liss, 1985: 131-51.

21 Dixon WJ, Brown MB, Engelman L, Jennrich RI. BMDP statistical software manual. In: Bryan A, Covello E, Dula $M$, eds. BMDP data manager manual. Los Angeles: BMDP, 1990.

22 Kennedy C, Sakurada O, Shinohara M, Miyaoka M. Local cerebral glucose utilization in the newborn Macaque monkey. Ann Neurol 1982; 12: 333-40.

23 De Vasconcelos AP, Colin C, Desor D, Divry M, Nehlig A. Influence of early neonatal phenobarbital exposure on cerebral energy metabolism and behavior. Exp Neuro 1990; 108: 176-87.

24 Theodore WH. Antiepileptic drugs and cerebral glucose metabolism. Epilepsia 1988; 29: S48-55. 